\title{
The prevalence of gastro-oesophageal reflux disease and its relationship with diet and obesity among public school teachers in Abeokuta, south-west Nigeria
}

\author{
KOLAWOLE O. AKANDE ${ }^{*}$, GRACE T. FADUPIN ${ }^{2}$ and MOSES A. AKINOLA ${ }^{3}$ \\ ${ }^{1}$ Department of Medicine, University of Ibadan, Nigeria \\ ${ }^{2}$ Departments of Nutrition and Dietetics, University of Ibadan, Nigeria \\ ${ }^{3}$ Department of Surgery, Babcock University, Ilishan-Remo, Nigeria
}

\begin{abstract}
Background: Gastro-oesophageal reflux disease (GORD) is a common chronic disorder in the high-income countries; and thought to be rare in low- and middle-income-countries. Lifestyle and diets have been suggested among others, as risk factors contributing to the development and severity of GORD. The objective of this study was to determine the prevalence of GORD and its association with dietary items and obesity among public school teachers in Abeokuta, south-western Nigeria.

Methods: School teachers from 24 randomly selected public schools in Abeokuta were involved in the study. A self-administered questionnaire was used to obtain information on respondents' bio data, food frequency and Carlson-Dent scores were calculated for each respondent. A score of 4 and above on the Carlsson-Dent questionnaire was considered diagnostic of GORD. Each respondent had his or her weight, height, waist circumference and hip circumference measured. Body mass index and waist-hip ratio were calculated for each respondent.

Results: A total of 550 teachers participated in the study. The prevalence of GORD was found to be $13.8 \%$ among the teachers. There was a significant association between chocolate consumption and frequency of GORD ( $p=0.01)$. There was no association between consumption of soft drinks $(p=0.673)$, kola nut $(P=0.451)$, beer $(p=0.674)$, bitter kola $(0.425)$, groundnut $(0.442)$, cowpeas $(p=0.442)$, walnut $(p=0.905)$, gari $(p=0.931)$, fufu $(p=0.249)$ and lafun $(p=0.480)$ and the frequency of GORD. Similarly, no association was found between obesity (BMI, $p=0.738)$, waist-hip ratio $(p=0.56)$ and the frequency of GORD.

Conclusion: GORD is common among public school teachers in Abeokuta with a prevalence of 13.8\%. Except for consumption of chocolate, no association was found between frequency of GORD and consumption of majority of the dietary items considered in this study.
\end{abstract}

Keywords: gastro-oesophageal, reflux disease, diet, obesity, Nigeria

\section{Introduction}

Gastro-oesophageal reflux disease (GORD) is a chronic condition that develops when the reflux of gastric contents causes troublesome symptoms and or complications. The cardinal symptoms of GORD are heartburns and regurgitation. GORD also has extra oesophageal manifestations including asthma, cough, laryngitis and dental erosions among others (Vakil et al., 2006). Complications of GORD include increased health care cost, impaired quality of life and adenocarcinoma of the oesophagus (Green et al., 2000; Chen et al., 2005; Ajmera et al., 2014). It is a common disease in the high-income countries affecting 10-38\% of the adult population (Locke et al., 1997; Kennedy \& Jones, 2000). It was reported to be rare in low and middle-income countries (Segal, 2001; Ho, 2008) though later studies showed that GORD is prevalent (Sharma et al., 2011). A validated symptom score based on heartburns and regurgitation is a useful diagnostic tool to conduct epidemiological studies in GORD (Carlsson et al., 1998).

The relationship between diet and GORD is inconclusive. El-Serag et al. (2005) and Nebel et al. (1976) found some relationship between GORD and some types of diets either as a risk factor or

\footnotetext{
${ }^{*}$ Correspondence E-mail: seyiakande2001@yahoo.com
} 
precipitants. Studies by Ruhl \& Everhart (1999) and Nandurkar et al. (2004) did not find such relationship. Apart from Nwokediuko (2009) who found a relationship between consumption of Kola nut and GORD among medical students, there is paucity of data on the relationship between diet and GORD in Nigeria. There are few studies on the prevalence of GORD in Nigeria and almost all were hospital based (Nwokediuko, 2009; Akere et al., 2010; Ajayi et al., 2013). Ajayi et al. (2013) reported a prevalence of $27 \%$ among patients that had upper gastro intestinal endoscopy in south-west Nigeria while Nwokediuko (2009) reported a prevalence of $26 \%$ among medical students in south-east Nigeria. There was therefore a need to conduct a population-based study that will reflect better the true prevalence of GORD in Nigeria. The objective of this study was to determine the prevalence of GORD and its association with dietary items and obesity among public school teachers in Abeokuta, south-western Nigeria.

\section{Materials and Methods}

\section{Study site and subjects}

The study was carried out among public school teachers in Abeokuta, Nigeria in January-February, 2015. Abeokuta is the largest and the capital city of Ogun State in south-west Nigeria with a population of 593,100. Abeokuta is made up of Abeokuta North Local government, Abeokuta South Local government and parts of Odeda and Obafemi Owode local government council areas. Using a prevalence of $26 \%$ (Nwokediuko, 2009), precision of $2 \%$, confidence interval of $95 \%$ and an allowance of $10 \%$ loss, a minimum sample size of 392 was obtained. A list of all government owned secondary and primary schools in Abeokuta were obtained from the Ministry of Education, Ogun State. Four primary and 4 secondary schools were randomly selected (balloting) from each of Abeokuta North and South Local Government areas while 2 primary and 2 secondary schools were similarly selected from each of Odeda and Obafemi Owode Local Government Areas that were part of Abeokuta Municipality. At least 20 consecutive consenting teachers were recruited from a total of 24 schools. Pregnant teachers and those who were apparently ill were excluded.

\section{Data collection}

Each respondent was asked to fill a self-administered Carlsson-Dent (Carlsson et al., 1998) and food frequency questionnaire. The bio data information collected included age, sex, tribe, marital status and the grade level in the teaching profession. Carlsson-Dent questionnaire is a 7-item questionnaire that is used for the diagnosis of gastro oesophageal reflux diseases. A score of 4 and above on the questionnaire was considered diagnostic of GORD (Carlsson et al., 1998). The dietary items included in the questionnaire were soft drinks, kola nut, alcohol in various forms, bitter kola, groundnut, cowpea in various forms, walnut, cigarette and cassava flours (gari, fufu, lafun).

Each respondent had his or her height $(\mathrm{m})$ weight $(\mathrm{kg})$, waist circumference $(\mathrm{cm})$, and hip circumference $(\mathrm{cm})$ measured. Weight was taken using bathroom scale while height was taken using standiometers. Both the waist and hip circumferences were taken with stretch-resistant tape measures. Waist circumference was taken mid-way between the last palpable rib and the iliac crest while the hip circumference was taken along widest portion of the buttocks (WHO, 2008). Body mass index (BMI) $\left(\mathrm{kg} / \mathrm{m}^{2}\right)$ and waist hip ratio were calculated for each respondent. BMI of 25-29.9 $\mathrm{kg} / \mathrm{m}^{2}$ and above was considered to be overweight while 30 and above was considered to be obese. Waist-Hip ratio greater than 0.85 was considered to be abnormal for the female respondents while greater than 0.9 was considered abnormal for the male respondents (WHO, 2008). 


\section{Data analysis}

The data was analysed using Statistical Package for Social Sciences version 16. A total of 587 respondents were recruited for the study out of which only 550 were analysed. The remaining 37 were excluded from analysis because of incomplete filling of the questionnaires. Chi square was used to investigate the relationship between each dietary item and GORD. P-value less than 0.05 was considered significant.

\section{Ethical consideration}

Ethical approval was obtained from the ethics committee of Sacred Heart Hospital, Lantoro, Abeokuta. Written consent was taken from the individual respondent. Permission to conduct the study was sought and granted by the respective school administration.

\section{Results}

Of the 550 respondents, 140 (25.5\%) were males and 410 (74.5\%) were females. Their age ranged from 18 to 58 years with a mean age of $39.7 \pm 9.1$ years (Figure 1 ). Twenty-three (95.1\%) of the respondents were the Yoruba, 20 (3.6\%) Ibo, 2 (0.4\%) Hausa while $5(0.9 \%)$ were from other tribes. Four hundred and seventy-five respondents (86.4\%) were married, 71 (12.9\%) were single and 4 (0.7\%) were widows or widowers. The body mass indices of the respondents ranged from 16.7 to $44.0 \mathrm{~kg} / \mathrm{m}^{2}$ with a mean of $27.1 \pm 5.5 \mathrm{~kg} / \mathrm{m2}$. The waist hip ratio of the respondents ranged from 0.55 to 1.9 with a mean of $0.86 \pm 0.09 \mathrm{~kg} / \mathrm{m} 2$ (Table 1). Using BMI, $1.75 \%$ were underweight, $36.66 \%$ were normal, $35.41 \%$ were overweight while $26.18 \%$ were obese. Using weight hip ratio, $49.9 \%$ of the respondents had normal value while $50.1 \%$ had high values.
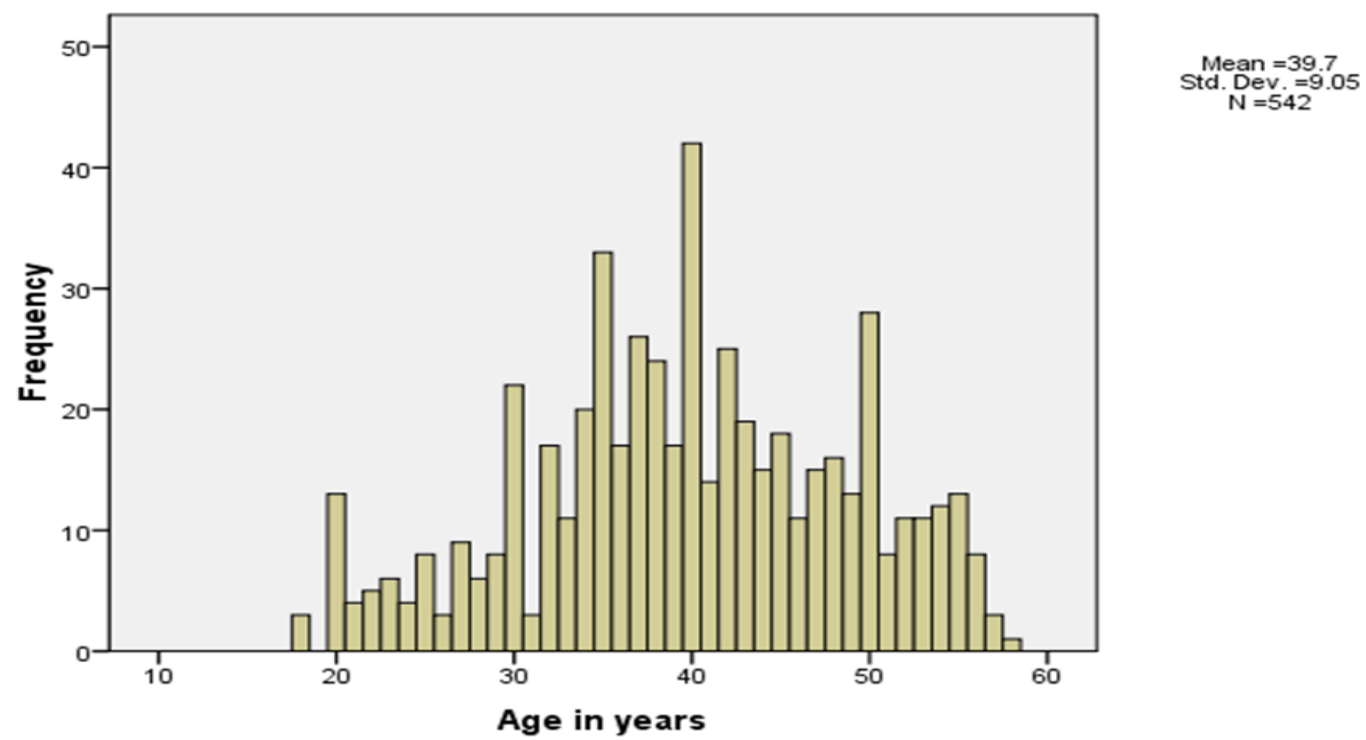

Figure 1: Distribution of the respondents' ages in years

Seventy-six patients out of the 550 respondents had GORD giving a prevalence of $13.8 \%$. Twenty male $(14.3 \%)$ and $56(13.7 \%)$ female respondents had GORD $(p=0.34)$. Seventy $(13.4 \%)$ of the Yoruba respondents had GORD, while $6(30 \%)$ of the Ibo subjects had GORD and none of the two Hausa subjects had GORD $(P=1.1)$. The mean age of the respondents with GORD was $39.9 \pm 9.3$ years while that of the respondents without GORD was 39.7 \pm 9.1 years $(p=0.96)$. 
Table 1: Anthropometric measurements of the respondents

\begin{tabular}{|c|c|c|c|c|c|}
\hline Variable & & Minimum & Maximum & Mean (SD) & P-value \\
\hline \multirow[t]{3}{*}{ Height (m) } & & 1.2 & 1.86 & $1.63(0.09)$ & \\
\hline & Male & & & $1.69(0.09)$ & 0.066 \\
\hline & Female & & & $1.60(0.08)$ & \\
\hline \multirow[t]{3}{*}{ Weight (kg) } & & 41 & 120 & $71.6(14.2)$ & \\
\hline & Male & & & $70.92(13.2)$ & 0.164 \\
\hline & Female & & & $71.8(14.6)$ & \\
\hline \multirow[t]{3}{*}{ BMI (kg/m2) } & & 16.7 & 44 & $27.1(5.5)$ & \\
\hline & Male & & & $24.7(4.3)$ & 0.04 \\
\hline & Female & & & $27.9(5.6)$ & \\
\hline \multirow[t]{3}{*}{ Hip circumference $(\mathrm{cm})$} & & 32 & 179 & $103.6(12.9)$ & \\
\hline & Male & & & $95.2(13.1)$ & 0.7 \\
\hline & Female & & & $106.4(11.56)$ & \\
\hline \multirow[t]{3}{*}{ Waist circumference $(\mathrm{cm})$} & & 31 & 179 & $90.4(13.9)$ & \\
\hline & Male & & & $85.4(15.0)$ & 0.48 \\
\hline & Female & & & $92.1(13.2)$ & \\
\hline \multirow[t]{3}{*}{ Waist: Hip ratio } & & 0.55 & 1.9 & $0.86(0.09)$ & \\
\hline & Male & & & $0.89(0.08)$ & 0.82 \\
\hline & Female & & & $0.86(0.09)$ & \\
\hline
\end{tabular}

Key: SD=standard deviation

Table 2: The relationship between GORD and frequency of taking different dietary items

\begin{tabular}{|c|c|c|c|c|c|c|c|c|}
\hline \multirow{2}{*}{$\begin{array}{l}\text { Dietary } \\
\text { Items }\end{array}$} & \multirow[t]{2}{*}{ GORD } & \multicolumn{6}{|c|}{ Frequency of taking different dietary items } & \multirow[t]{2}{*}{$P$ value } \\
\hline & & $\mathbf{0}$ & $<1 /$ month & $2-3 /$ month & 1-2/week & 3-4/week & Everyday & \\
\hline \multirow{2}{*}{ Beer } & Yes & 14.0 & 12.9 & $5 \cdot 3$ & 42.9 & 20.0 & 0 & \multirow{2}{*}{0.674} \\
\hline & No & 86.0 & 87.1 & 94.7 & 57.1 & 80.0 & 100 & \\
\hline \multirow{2}{*}{ Soft drinks } & Yes & 10.4 & $15 \cdot 5$ & 11.0 & 12.6 & 20.0 & 18.2 & \multirow{2}{*}{0.710} \\
\hline & No & 89.6 & 84.5 & 69.0 & 87.4 & 80.0 & 81.8 & \\
\hline \multirow{2}{*}{ Kola nut } & Yes & 14.2 & 11.1 & $33 \cdot 3$ & 0 & 0 & 0 & \multirow{2}{*}{0.451} \\
\hline & No & 85.8 & 88.9 & 66.7 & 100 & 100 & 100 & \\
\hline \multirow[b]{2}{*}{ Bitter Kola } & Yes & 13.0 & 15.5 & 11.1 & 12.5 & 60.0 & 0 & \multirow[b]{2}{*}{0.425} \\
\hline & No & 87.0 & 84.5 & 88.9 & 87.5 & 40.0 & 100 & \\
\hline \multirow{2}{*}{ Ground nut } & Yes & 18.0 & $9 \cdot 3$ & 17.7 & 20.2 & 7.4 & 0 & \multirow[b]{2}{*}{0.442} \\
\hline & No & 82.0 & 90.7 & 82.3 & 79.8 & 92.6 & 100 & \\
\hline \multirow{2}{*}{ Beans } & Yes & 33.3 & 12.1 & 11.8 & 16.4 & $13 \cdot 3$ & 6.7 & \multirow{2}{*}{0.381} \\
\hline & No & 66.7 & 87.9 & 88.2 & 83.6 & 86.7 & $93 \cdot 3$ & \\
\hline \multirow{2}{*}{ Walnut } & Yes & 13.7 & 13.8 & 15.6 & 10.0 & 17.6 & 13.3 & \multirow{2}{*}{0.905} \\
\hline & No & 91.8 & 88.4 & 85.5 & 70.0 & 87.5 & 76.2 & \\
\hline \multirow{2}{*}{ Chocolate } & Yes & 86.7 & 86.2 & 84.4 & 90.0 & 82.4 & 86.7 & \multirow{2}{*}{0.001} \\
\hline & No & 8.2 & 11.6 & $14 \cdot 5$ & 30.0 & 12.5 & 23.8 & \\
\hline \multirow[t]{2}{*}{ Gari } & Yes & 11.8 & 11.1 & $13 \cdot 3$ & 16.9 & 15.1 & 0 & \multirow{2}{*}{0.931} \\
\hline & No & 88.2 & 88.9 & 86.7 & 83.1 & 84.9 & 100 & \\
\hline \multirow{2}{*}{ Fufu } & Yes & $13 \cdot 5$ & $9 \cdot 9$ & 20.2 & $15 \cdot 9$ & 12.1 & 18.2 & \multirow{2}{*}{0.2} \\
\hline & No & 86.5 & 90.1 & 79.8 & 84.1 & 87.9 & 81.8 & \\
\hline \multirow{2}{*}{ Lafun } & Yes & 9.8 & 17.0 & 13.1 & 13.0 & 17.1 & 9.1 & \multirow{2}{*}{0.462} \\
\hline & No & 90.2 & 83.0 & 86.9 & 87.0 & 82.9 & 90.9 & \\
\hline
\end{tabular}


From the food frequency questionnaire, $96(17.5 \%)$ respondents took cassava in different forms every day, while 45 (8.2\%) took cowpeas every day. Carbonated drinks, ground nuts, chocolate, beer, kolanut, bitter kola and walnut were taken every day by $27(4.9 \%), 21(4.2 \%), 21(3.8 \%), 9(1.7 \%), 2(0.4 \%)$, $6(1.1 \%)$, and $12(2.2 \%)$ respondents respectively. The $p$ values for the relationship between GORD and various dietary items were $0.381,0.931,0.710,0.442,0.001,0.674,0.451,0.425$, and 0.905 for cowpeas, gari, carbonated drinks, ground nut, chocolate, beer, kolanut, bitter kola and walnut, respectively (Table 2 ).

Twenty-five (13.2\%) of those with normal BMI had GORD while (30) $15.4 \%$ of those who were overweight had GORD and $21(13.3 \%)$ of those that were obese had GORD ( $p=0.738)$. With the use of waist hip ratio, $36(13.3 \%)$ of those who had normal value had GORD while $39(14.2 \%)$ of those with high value had GORD $(p=0.560)$.

\section{Discussion}

The prevalence of GORD in this study was $13.8 \%$ and this suggests that GORD is actually common in this part of Nigeria. This falls within the wide range of prevalence reported elsewhere in the world (Locke et al., 1997; Kennedy \& Jones, 2000; Wang et al., 2004; Mohammed et al., 2005). The wide range of the prevalence across these studies could be due to differences in the definitions of GORD. For instance, in the study by Mohammed et al. (2005) GORD was defined as occurrence of heartburn at least once a week while in this study the Carlsson-Dent technique (Carlsson et al., 1998), which is more specific and rigorous in its definition of GORD was used. Nwokediuko (2009) using the same Carlsson-Dent technique, however reported a higher prevalence in south-east Nigeria. The difference between the Nigerian studies may be due to the difference in the age groups of the respondents in the two studies. While their respondents were relatively young medical students, older group (teachers) were the respondents in this study. An Indian study found younger age as a risk factor for occurrence of GORD (Kumar et al., 2011).

The socio-demographic characteristics of the respondents did not significantly affect the prevalence of GORD in this study. This agrees with the study of Nwokediuko (2009) in South-east, Nigeria in which there was no association between age, sex and the occurrence of GORD. In a study in India, Kumar et al. (2011) found GORD to be more common among the younger age group individuals. The lack of association between age and GORD in these two studies in Nigeria may be because the two study were done in specific populations of students and teachers while Kumar et al. (2011) studied a more varied subjects in terms of their age range.

Although the findings of our study did not indicate any association between consumption of soft drinks and frequency of GORD, soft drinks have been described to predispose to GORD because of their high acidity, carbonation and ability to lower oesophageal sphincter (Johnson et al., 2010). In a similar study in the United States, Kubo et al. (2014), did not find any association between ingestion of soft drinks and GORD occurrence. However, there are different types of soft drinks with different contents, acidity and carbonation making them to predispose to GORD to different extent. This study did not explore the different types of carbonated drinks taken by the respondents. Kola nuts are common snacks in Nigeria especially in the northern parts. They are thought to be refluxogenic because of the caffeine content in them (Nwokediuko, 2009). This study did not show any association between consumption of kolanut and GORD occurrence. The reason for this is not clear although one does not know whether the same species of kolanut being consumed in south-west is the same as that consumed in south-east of Nigeria where Nwokeduiko (2009) carried out his own study. Different species of kola nut may have different caffeine contents. In this study no association was observed between intake of beer and frequency of GORD, similar to the observations by Nwokeduiko (2009) and Nilson et al. (2004). In contrary, Kubo et al. (2014), found some association 
between alcohol and GORD. The inconsistency is not surprising as there are various forms of alcohol with different ethanol content. Moreover, the pattern of alcohol drinking may also differ in subjects.

A significant association was observed between consumption of chocolate and GORD in this study. This is not surprising because chocolate contain caffeine and is high in fat acids. Similar findings have been reported elsewhere (Dore et al., 2005). In a study by El-Serag et al. (2005) a positive association between high fat diet and GORD was observed. In our study, one-fifth of the teachers reported taking chocolate at least once a week. In this study, no association was found between frequency of GORD and consumption of bitter kola, ground nut, cowpeas and different forms of cassava meals. No previous work has been done to investigate the association between these local diets and GORD to the best of our knowledge.

The link between obesity and GORD has been a subject of several studies with conflicting reports. This study did not show any association between obesity either as determined by BMI or waist-hip ratio and GORD. Hampel et al. (2005) in a meta-analysis, found a significant association between GORD symptoms and obesity while Corley \& Kubo (2006) reported conflicting findings among European subjects. Akere et al. (2010) found a weak association between BMI and symptoms of GERD among Nigerian subjects. The reasons for little or no association between obesity and GORD in our population is not obvious.

This study had two obvious limitations. One, it was done among the teachers alone who represent just a specific segment and social class of the society. Secondly, the amount and the manner of preparation of the dietary items were not taking cognizance of the relationship between them and GORD. In conclusion, GORD is a common gastrointestinal disorder among public school teachers in Abeokuta, Nigeria and a significant association was observed between its prevalence and consumption of chocolate.

\section{Competing Interest}

The authors declare they have no competing interest.

\section{Authors' contribution}

KOA conceptualized the study. KOA and MAA collected and analysed the data. GTF supervised the conceptualization, data collection and analysis of the study. KOA and MAA wrote the initial draft of the manuscript while GTF reviewed the manuscript. All the Authors read and approved the manuscript.

\section{Acknowledgements}

We acknowledge students of Human Nutrition from Federal University of Agriculture Abeokuta and Federal Polytechnic Ilaro who were on Industrial attachment at the State Specialist Hospital, ljaiye Abeokuta in 2015. They were trained and served as data collectors for the study.

\section{References}

Ajayi, A.O., Solomon, O.A. \& Adegun, P.T. (2013) Prevalence of GERD in Ado-Ekiti, Nigeria. Nigerian Journal of Gastroenterology and Hepatology 5:79-84.

Ajmera, M., Raval, A.D., Shen, C. \& Sambamoorthi, U. (2014) Explaining the increased health care expenditures associated with gastroesophageal reflux disease among elderly medicare 
beneficiaries with chronic obstructive pulmonary disease: a cost-decomposition analysis. International Journal of Chronic Obstructive Pulmonary Disease 9:339-348.

Akere, A., Adebusoye, L.A. \& Afolabi, B.A. (2010) Association between Body mass index and gastroesophageal reflux disease in blacks. Nigerian Journal of Gastroenterology and Hepatology 2:89-94.

Carlsson, R., Dent, J., Bolling-Sternevald, E., Johnsson, F., Junghardm O., Lauritsen, K., Riley, S. \& Lundell, L. (1998) The usefulness of a structured questionnaire in the assessment of symptomatic gastroesophageal reflux disease. Scandinavian Journal of Gastroenterology 33:1023-1029.

Chen, M., Xiong, L., Chen, H., Xu, A., He, L. \& Hu, P. (2005) Prevalence, risk factors and impact of gastroesophageal reflux disease symptoms: a population-based study in South China. Scandinavian Journal of Gastroenterology 40:759-767.

Corley, D.A. \& Kubo, A. (2006) Body mass index and gastroesophageal reflux disease: a systematic review and meta-analysis. American Journal of Gastroenterology 101:2619-2628.

Dore, M.P., Maragkoudakis, E., Fraley, K., Pedroni, A., Tadeu, V., Realdi, G., Graham, D.Y., Delitala, G. \& Malaty, H.M. (2008) Diet, lifestyle and gender in gastro-esophageal reflux disease. Digestive Disease Science 53:2027-2032.

El-Serag, H.B., Satia, J.A. \& Rabeneck, L. (2005) Dietary intake and the risk of gastro-oesophageal reflux disease: A cross sectional study in volunteers. Gut 54:11-17.

Green, J.A., Amaro, R. \& Barkin, J.S. (2000) Symptomatic gastroesophageal reflux as a risk factor for esophageal adenocarcinoma. Digestive Disease Science 45:2367-2368.

Hampel, H., Abraham, N.S. \& El-Serag, H.B. (2005) Meta-analysis: obesity and the risk for gastroesophageal reflux disease and its complications. Annals of Internal Medicine 143: 199-

Ho, K.Y. (2008) Gastroesophageal reflux disease in Asia: a condition in evolution. Journal of Gastroenterology and Hepatology 23:716-722.

Johnson, T., Gerson, L., Hershcovici, T., Stave, C. \& Fass, R. (2010) Systematic review: the effects of carbonated beverages on gastro-oesophageal reflux disease. Alimentary Pharmacology \& Therapeutics 31:607-614.

Kennedy, T. \& Jones, R. (2000) The prevalence of gastro-oesophageal reflux symptoms in a UK population and the consultation behaviour of patients with these symptoms. Alimentary Pharmacology \& Therapeutics 14:1589-1594.

Kubo, A., Block, G., Quesenberry, C.P., Buffler, P. \& Corley, D.A. (2014) Dietary guideline adherence for gastroesophageal reflux disease. BMC Gastroenterology 14: 144-152.

Kumar, S., Sharma, S., Norboo, T., Dolma, D., Norboo, A., Stobdan, T., Rohatgi, S., Munot, K., Ahuja, V. \& Saraya, A. (2011) Population based study to assess prevalence and risk factors of gastroesophageal reflux disease in a high-altitude area. Indian Journal of Gastroenterology 30:135-143.

Locke, G.R., Talley, N.J., Fett, S.L., Zinsmeister, A.R. \& Melton, L.J. (1997) Prevalence and clinical spectrum of gastroesophageal reflux: a population-based study in Olmsted County, Minnesota. Gastroenterology 112:1448-1456.

Mohammed, I., Nightingale, P. \& Trudgill, N.J. (2005) Risk factors for gastro-oesophageal reflux disease symptoms: a community study. Alimentary Pharmacology \& Therapeutic 21:821-827.

Nandurkar, S., Locke, G.R., Fett, S., Zinsmeister, A.R., Cameron, A.J. \& Talley, N.J. (2004) Relationship between body mass index, diet, exercise and gastro-oesophageal reflux symptoms in a community. Alimentary Pharmacology \& Therapeutics 20:497-505.

Nebel, O.T., Fornes, M.F. \& Castell, D.O. (1976) Symptomatic gastroesophageal reflux: incidence and precipitating factors. American Journal of Digestive Disease 21:953-956. 
Nwokediuko, S. (2009) Gastroesophageal Reflux Disease: A Population Based Study. Gastroenterology Research 2:152-156.

Ruhl, C.E. \& Everhart, J.E. (1999) Overweight, but not high dietary fat intake, increases risk of gastroesophageal reflux disease hospitalization: the NHANES I Epidemiologic Follow-up Study. First National Health and Nutrition Examination Survey. Annals of Epidemiology 9:424435.

Segal, I. (2001) The gastro-oesophageal reflux disease complex in sub-Saharan Africa. European Journal of Cancer Prevention 10: 209-212

Sharma, P.K., Ahuja, V., Madan, K., Gupta, S., Raizada, A. \& Sharma, M.P. (2011) Prevalence, severity, and risk factors of symptomatic gastroesophageal reflux disease among employees of a large hospital in northern India. Indian Journal of Gastroenterology 30:128-234.

Vakil, N., van Zanten, S.V., Kahrilas, P., Dent, J., Jones, R. \& Global Consensus Group. (2006) The Montreal definition and classification of gastroesophageal reflux disease: A global evidencebased consensus. American Journal Gastroenterology 101:1900-1920.

WHO (2008) Waist Circumference and Waist-Hip Ratio. http://www.who.int/nutrition/publications/obesity/WHO_report_waistcircumference_and_w aisthip_ratio/en/. Accessed August 26, 2018.

Wang, J-H., Luo, J-Y., Dong, L., Gong, J. \& Tong, M. (2004) Epidemiology of gastroesophageal reflux disease: A general population-based study in Xi'an of Northwest China. World Journal of Gastroenterology 10:1647-1651. 